\title{
A Basic Formula for Effective International Student Services
}

\author{
David L. Di Maria \\ University of Maryland, Baltimore County, USA
}

The effective delivery of support services for international students has been the subject of professional discourse for nearly a century (Wheeler et al., 1925). While scholars have long examined the problem of student attrition, early retention models (Spady, 1970; Tinto, 1988) applied anthropological, psychological, and sociological theories in ways that mostly ignored the intuitional responsibility and capacity to serve culturally diverse individuals. Furthermore, an analysis of 50 years of student affairs research found that international students were mostly excluded (Pope et al., 2009). It was not until the establishment of the Journal of International Students that international students began to receive regular attention within the academic literature.

International student advisors have an important role to play in helping international students adjust to their host communities and institutions. However, changes to student immigration regulations has resulted in an increased emphasis on immigration compliance (Boyd, 2008; Rosser et al., 2007) and lowered the capacity of some international student offices to provide nonimmigration services.

The quality of international student services, whether immigration or not, is generally dependent on formal and informal processes of which multiple stakeholders are a part. Thus, a small change to one element has the potential to affect the whole. In order to maximize efficiency and effectiveness of services offered, international student advisors may benefit from applying a systems perspective as summarized by the following formula:

$$
\mathrm{ISS}=[\mathrm{PM}+(\mathrm{LM}+\mathrm{I}+\mathrm{V})]+\mathrm{CI}
$$

International Student Services $=[$ Process Mapping $+($ Lean Mindset + Intentionality + Value) $]+$ Continuous Improvement 


\section{Process Mapping}

Process mapping is a useful tool for understanding the interrelationships of all the specific elements that allow for a specific product or service (McDonald, 2010). For instance, a process map may be used to visualize the series of steps, decisions, and delays that begin when someone applies for admission as an international student and ends when that person receives the necessary documents to apply for a student visa. The elements are each mapped individually and their relationships to each other are visually mapped to create a workflow diagram. This dynamic flowcharting activity makes it possible to understand how each part contributes to the whole and the downstream consequences of interventions.

\section{Lean Mindset}

International student advisors should strive to develop a lean mindset. This includes commitment to identifying wastes and improving the flow of processes that deliver campus-based programs and services (Balzer, 2010). Such wastes may include requiring international students to complete actions that are unnecessary or overly burdensome - for instance, requiring a student to obtain signatures on a paper form in order to request authorization for curricular practical training when free cloud-based solutions exist that would expedite and simplify the process for all involved. As the workload of international student advisors increases due to additional immigration compliance requirements, it is critical to be able to maximize capacity by eliminating waste.

\section{Intentionality}

International student services should be considered an important part of the cocurriculum. While an orientation program for new international students may include a shopping trip to the local mall, an intentional approach to this service would be to leverage the activity as a means for teaching students how to use the local bus system. This would not only accomplish the basic goal of helping students obtain access to needed goods, but it would also help them acquire the knowledge and skills necessary to travel confidently around their host community. Thus, programming for international students should include strategies to promote desired learning outcomes (Harper \& Antonio, 2008; Harper, 2011).

\section{Value}

When analyzing components of international student services, it is important to assess parts of the process using the following criteria:

1. Adds value from the student's perspective,

2. Does not add value from the student's perspective, but is required, and

3. Does not add value from the student's perspective nor is it required. 
The goal of assessing value is to ensure most, if not all, of the components that make up the process add value from the perspective of the student. This helps to instill a higher level of satisfaction with the services offered and it keeps advisors from engaging in activities that detract from the overall mission of supporting international students.

\section{Continuous Improvement}

The work of enhancing international student services is never complete. Rather, the international student office staff should commit to regularly reviewing and refining the services they offer using the elements included in the formula.

\section{CONCLUSION}

A systems perspective is helpful for understanding and ensuring the effectiveness of international student services. While international student advisors may be exceptional as individual contributors to a given process, failure to see the interdependencies between their work and the work of others who touch the process can result in misalignment in expectations and experiences on the part of the student. The formula presented in this essay provides a framework by which international student services may be designed for maximum effectiveness, efficiency and value.

\section{REFERENCES}

Balzer, W. (2010). Lean higher education. Productivity Press.

Boyd, L. (2008). A study of how international student services and policies have changed as a result of $9 / 11$ [Ed.D. Dissertation, Boston University]

Harper, S., \& antonio, a. (2008). Not by accident: Intentionality in diversity, learning and engagement. In S. Harper (Ed.), Creating inclusive campus environments for cross-cultural learning and student engagement (pp. 1-18). NASPA.

Harper, S. (2011). Strategy and intentionality in practice. In J. Schuh, R. Jones, S. Harper \& S. Komives. Student services: A handbook for the profession (pp. 287302). Jossey-Bass.

McDonald, M. (2010). Improving business processes. Harvard Business School Publishing.

Pope, R., Mueller, J., \& Reynolds, A. (2009). Looking back and moving forward: Future directions for diversity research in student affairs. Journal of College Student Development, 50(6), 640-658.

Rosser, V., Hermsen, J., Mamiseishvili, K., \& Wood, M. (2007). A national study examining the impact of SEVIS on international student and scholar advisors. Higher Education, 54, 525-542.

Spady, W. (1970). Dropouts from higher education: An interdisciplinary review and synthesis. Interchange 1(1), 64-85.

Tinto, V. (1988). Stages of student departure: Reflections on the longitudinal character of student leaving. The Journal of Higher Education, 59(4), 438-455. 
Wheeler, W., King, H., \& Davidson, A. (1925). The foreign student in America (pp. 381). Commission on Survey of Foreign Students, the Young Men's Christian Association and the Young Women's Christian Association.

DAVID L. DI MARIA, EdD, is Associate Vice Provost for International Education at the University of Maryland, Baltimore County. His major research interests lie in the area of internationalization of higher education, international education leadership, international student mobility and international student services. Email: dimaria@,umbc.edu 